\title{
Dynamic coupling of reef fish replenishment and oceanographic processes
}

\author{
M. J. Milicich* \\ School of Environmental Studies, Griffith University, Nathan, Brisbane, Queensland 4111, Australia
}

\begin{abstract}
Oceanographic processes have been shown to play a pivotal role in the control of recruitment variability in some commercial, northern temperate fish populations. This study investigates the link between inter-annual changes in larval supply and wind stress for unexploited reef fish populations at Lizard Island, northern Great Barrier Reef. For the first time, this relationship is analysed separately for front-reef and back-reef habitats and results for 3 major reef fish familes (Pomacentridae, Apogonidae, Blenniidae) reveal that the link between wind stress and larval supply appears to be habitat-dependent. In the back-reef habitat, there appears to be a positive correlation between interannual changes in the frequency of onshore winds and the level of larval supply. This phenomenon is associated with large-scale changes in weather systems, suggesting that the relationship may be predictable at a region-wide scale. Results for the front-reef habitat suggest that the effect of wind stress on inter-annual levels of larval supply is less important. Survival and advection of earlier larval stages may be more influential in determining fluctuations in the magnitude of replenishment to this habitat. Although not helpful in predicting inter-annual changes in larval supply, a local retention mechanism may keep larval supply into this habitat elevated above that of the back-reef side. Comparison of these results with a non-reef mixed-age group of schooling pelagic fishes suggests that these patterns are a unique feature of the replenishment process.
\end{abstract}

KEY WORDS: Larval supply $\cdot$ Hydrodynamics $\cdot$ Reef fishes

\section{INTRODUCTION}

There is a strong, historic tradition among fisheries scientists to search for correlations between the magnitude of recruitment and the amplitude of environmental variables. Physical factors such as temperature, rainfall, salinity, sea level, river discharge, storms, eddies, Ekman transport, alongshore transport indices, upwelling, El Niño events, and wind stress have all been implicated in the control of recruitment variability via the transport and survival of the larval life history stage (e.g. Leggett et al. 1984, Sissenwine 1984, Anthony \& Fogarty 1985, Sinclair et al. 1985, Epifanio et al. 1989). By comparison with these detailed studies, the corresponding literature for unexploited reef fish populations is very sparse. Hydrodynamic processes such as the slicks of internal waves and Langmuir cir-

\footnotetext{
- Present address: Dept Marine Biology, James Cook University, Townsville, Queensland 4811, Australia
}

culations have been shown to influence distribution patterns and onshore movement of pre-settlement reef fish and invertebrates (e.g. Shanks 1983, Kingsford \& Choat 1985, 1986, Hamner \& Schneider 1986). Other oceanographic features close to reefs, such as topographically controlled fronts, island wake effects and tidal jets, have been identified as potentially important to larval supply (Alldredge \& Hamner 1980, Wolanski \& Hamner 1988, Kingsford et al. 1991).

However, only 2 published studies have attempted to correlate physical factors with actual levels of replenishment on reefs (tidal regimes, McFarland et al. 1985; current strength, Cowen 1985). Significantly, in both these studies, replenishment success was estimated from either the distribution of newly settled fish (McFarland et al. 1985) or from the relative size of consecutive year-classes (Cowen 1985). While these studies are insightful and suggest that hydrodynamic processes can have a high impact on replenishment variability, they fail to relate the physical environment 
of interest to the life history stage that actually inhabits that environment.

Recent technological advances (light traps; Doherty 1987. Milicich 1988) and the imaginative deployment of conventional gear (channel nets; Dufour 1991, Shenker et al. 1993) now allow the distribution patterns of fish just prior to settlement to be measured for a wide range of reef fish taxa (e.g. Milicich 1992). Direct investigation of the relationship between these larvae and their hydrodynamic environment may allow relevant hypotheses about the influence of physical factors on replenishment levels to be rigorously tested. This is the approach taken in the present study.

Lizard Island, situated on the northern Great Barrier Reef (GBR), is a continental land mass that supports a substantial fringing reef. A monitoring study revealed that replenishment of reef fish populations to Lizard Island is a complex process and evidence from a wide array of taxa suggests that there is a substantiai amount of decoupling in larval supply between the front-reef and back-reef habitats (Milicich \& Doherty 1994, companion article). As adults of many reef fish are relatively sedentary, differences in the process of larval supply between habitats may have a direct and lasting effect on the dynamics of local populations (Doherty \& Fowler 1994).

The decoupling of larval supply between habitats at Lizard Island suggests that replenishment cannot be simply attributed to large-scale uniform events that sweep reef habitats simultaneously. If hydrodynamic factors are important to this process, their effect appears to be influenced in some way by the reef itself. Previous studies interpreted a general link between physical factors and recruitment or year-class strength (Cowen 1985, McFarland et al. 1985) using biological data collected from single localities. In the light of these recent findings, the validity of such generalizations must be seriously questioned.

Investigation of the relationship between larval supply and hydrodynamic factors between habitats, and years, at Lizard Island on the northern GBR is a primary aim of the present study. Lizard Island $\left(14^{\circ} 40^{\prime} \mathrm{S}\right.$, $145^{\circ} 28^{\prime} \mathrm{E}$ ) is situated at the point where the westward ocean current bifurcates into the longshore northward and southward components of the East Australia Current (EAC). This peculiarity means that currents in the region are minimally affected by the EAC. Although shifts in the exact position of the bifurcation may alter influence of the EAC at Lizard Island, a 2 yr study by Frith et al. (1986) suggested that non-tidal currents at all depths in this area are primarily wind driven (Wolanski \& Ruddick 1981, Frith et al. 1986).

Wind stress is often the forcing function for the various complex oceanographic processes outlined above (Kingsford 1990) and its dominance in the Lizard
Island region suggests that variations in wind intensity may be important in determining replenishment levels. This hypothesis is explored in the present study. In addition, large-scale temporal and spatial changes in wind stress can often be identified by changes in barometric pressure (Andrews \& Pickard 1990). If true, this may generate considerable insight into the physical environment of settlement stage reef fish at a regional scale and trends in this factor are also investigated.

\section{METHODS}

Larval supply. Data on larval supply were obtained from daily light trap collections that were made at Lizard Island during the $1987-88$ and $1988-89$ recruitment seasons. In each year sampling started at the end of October or beginning of November and ended during the latter half of January. Details on the operation and method of deployment of the light traps are described elsewhere (Doherty 1987. Milicich 1988, 1992, Milicich et al. 1992). In the first sampling season 3 traps were depioyed in the front-reef and back-reef habitats, while in the following season 2 traps were used in each habitat (Fig. 1 in Milicich \& Doherty 1994). Traps were moored ca $250 \mathrm{~m}$ apart at a distance of between 300 and $500 \mathrm{~m}$ from the nearest reef margin in 18 to $23 \mathrm{~m}$ of water. The data series consist of a daily mean in the light trap catch calculated separately for each habitat. The years are concatenated according to the lunar calendar. This method was used since it was already established that larval supply at Lizard Island tends to be significantly associated with periods around or just following the new moon (Milicich unpubl.). Missing data were handled as described in Milicich et al. (1992). Briefly, where one trap failed in either habitat, the record from the remaining trap was used to represent larval supply. This was considered valid since time series taken from replicate traps are associated with a high degree of precision (Milicich 1992). If no data were available from a habitat on any one day, an estimated daily catch was derived by interpolation between points on the surrounding 2 days (this occurred on only 4 accasions). To err on the side of caution, we did not interpolate catch rates that were not bounded on either side by observed values.

Patterns of larval supply in these habitats are presented at the family level for 3 major reef fish families (Pomacentridae, Apogonidae, Blenniidae) and for a non-reef, schooling group that includes clupeids and atherinids. This latter group often form feeding schools around reefs that are composed of a mixed size-age range of individuals and these characteristics make them an ideal candidate to use as a 'control' in the comparisons with wind events. The family taxonomic 
level was chosen to increase the 'phase space' of the time-series as individual taxa replenish at different times during the season. 'Adding' individual taxa together increases the amount of replenishment per unit time in the series so that all significant periods of larval supply can be described. The only major family excluded from consideration in this study was the lethrinids; a general recruitment failure of these fish during the second season precluded any meaningful correlations between larval supply and hydrodynamic variables from being made.

Physical factors. Wind strength and direction data as well as barometric pressure were gathered by an automatic weather station operating at Willis Island, situated $1.5^{\circ} \mathrm{S}$ and $\mathrm{E}$ of Lizard Island. Wind strength and direction were combined by computing a single wind component. The component was defined as a positive value for every wind vector between $0^{\circ}$ and $180^{\circ}$, the size of which was determined by the wind speed (in $\mathrm{m} \mathrm{s}^{-1}$ ). By comparison, any wind vector between $180^{\circ}$ and $360^{\circ}$ was given a negative value. Thus, positive values describe winds moving onshore into the front-reef habitat, while negative values estimate the intensity of winds driving onshore into the back-reef habitat. The wind vector could have been more finely apportioned, perhaps into an along-shore as well as a cross-shelf component, however the interaction of wind and current with the topography around reefs can be highly significant. In the present case, the high continental island buffers and impedes the wind as it travels to reef habitats (Fig. 1 in Milicich \& Doherty 1994). Thus, the back-reef habitat is significantly sheltered from winds blowing from the easterly quadrant, while the opposite is true for the front-reef habitat. Choice of a coarse wind component was a deliberate attempt to include these simple but obviously important topographical effects. Vectors that were aligned exactly north or south were allocated as negative and positive values respectively. This division was based on the alignment and topography of the 2 habitats. Spatially, the 2 habitats are almost diametrically opposed to one another and parallel with the NE-SW axis. This means that winds from the north impinge into the back-reef habitat while winds from the south drive onshore into the front-reef habitat.

Although in terms of the large-scale physical environment being investigated, the differences in wind stress between Willis and Lizard Island may be expected to be trivial, drift between the 2 locations was checked by correlating wind data estimated visually at Lizard Island with the instrument data recorded at Willis Island (Fig. 1a). Data were filtered prior to calculation to remove any seasonality or short-term autocorrelation effects. Strong correlations were observed a

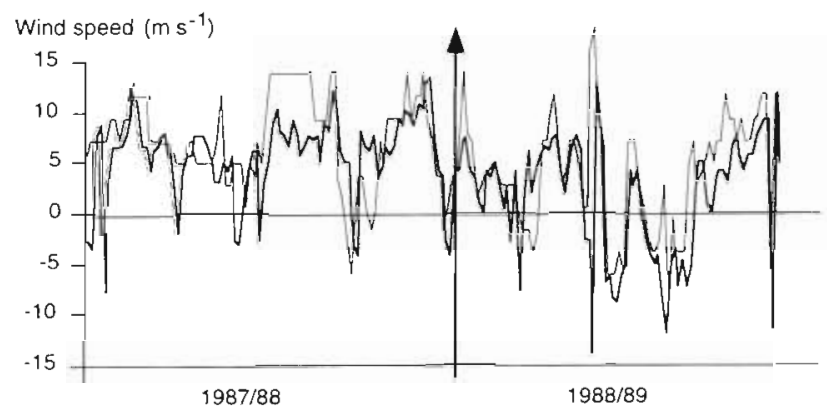

b

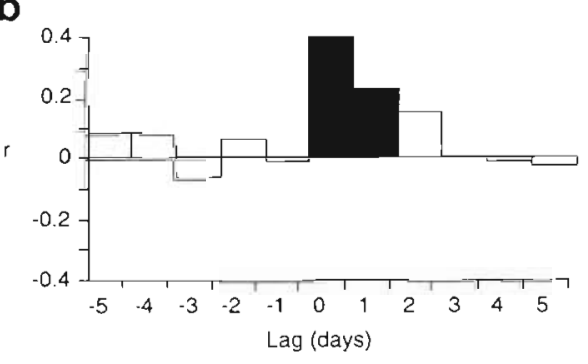

Fig. 1. (a) Comparison of wind stress data recorded visually at Lizard Island (thin line) and instrumentally at Willis Island over the 2 consecutive seasons. (b) Cross-correlation coefficients for the 2 time series ( -5 to $5 \mathrm{~d}$ lag). Solid bars refer to coefficients that are significant ( $95 \%$ level)

between the 2 data sets $(r=0.40,95 \% \mathrm{CI}=0.15$; Fig. 1b). Willis Island data were recorded 3 times a day and were considered a more accurate representation of the physical conditions occurring in the Lizard Island region.

Barometric pressure and the wind component data were analysed using time series analysis to identify long-term trends and seasonal cycles (Chatfield 1979). Cross-correlation functions between these 2 variables were then used to describe and interpret any relationship. Wind stress components were subsequently cross-correlated to the matching data on larval supply. In every case, calculation of cross-correlation functions was preceded by adequate filtering of the data to remove any trends, seasonal cycles or short-term autocorrelations. In all cases, any significant trend or seasonal removal was followed by fitting an autoregressive model of 1 to 3 terms. It should be noted that the time series of larval supply into the back-reef habitat was slightly shorter (by $10 \mathrm{~d}$ ) due to a consecutive period of missing trap data at the end of the first season of sampling. While this may be expected to bias results, larval supply at this time of year is always low (Milicich 1992) indicating that excluding this period from the analysis was unlikely to have caused ommission of any significant supply event. 


\section{RESULTS}

\section{Physical factors}

Changes in the barometric pressure over the 2 consecutive seasons of sampling are shown in Fig. $2 \mathrm{a}$. Although this series is not continuous between the 2 years, each sequence starts at a similar time in the year, so that inter-annual comparisons should not be confounded by a seasonal effect. Results of the time series analysis reveal that there is a significant negative long-term trend in the data that is evident in Fig. $2 \mathrm{a}[T(t)=-0.042 t+1010.1 ; \mathrm{p}=0.0000, \mathrm{p}=0.0000$, $\mathrm{r}^{2} \mathrm{adj}$, for $\left.\mathrm{df}=0.54\right)$. This indicates that there is a decline in barometric pressure both within a season and across the 2 consecutive seasons. The autocorrelation function of the residuals after trend removal indicate some degree of cycling in the data within any one seasur, and a seasonai model of period 18 produces a significant fit ( $p=0.0276$ ).

The wind component also showed a negative trend over the 2 sampling seasons $(T(t)=-0.064 t+12.86$, $p=0.0001, p=0.0000, r^{2}$ adj. (ur $\mathrm{d} \hat{f}=0.08$ ), indicating that wind stress into the back-reef habitat increased

a

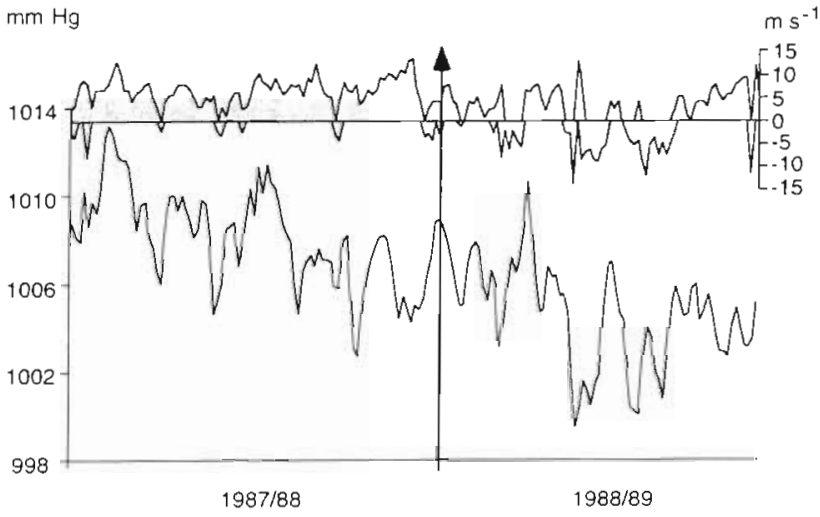

b

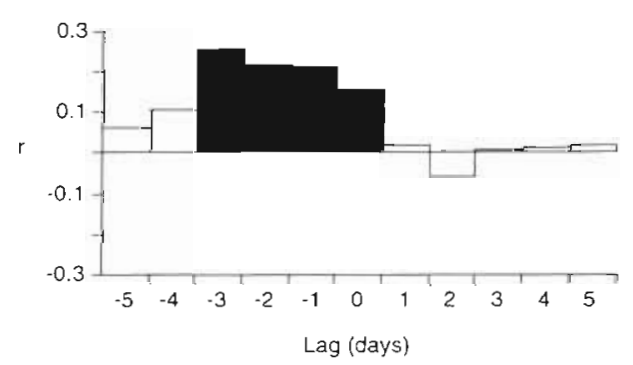

Fig. 2. (a) Trends in barometric pressure (line) and wind stress (shading). Positive values refer to winds 0 to $180^{\circ}$, negative values to winds from 180 to $360^{\circ}$ (b) Cross-correlation coefficients ( -5 to $5 \mathrm{~d} \mathrm{lag}$ ) of match between barometric pressure and wind stress data. Solid bars are significant at $\alpha=0.05$ a

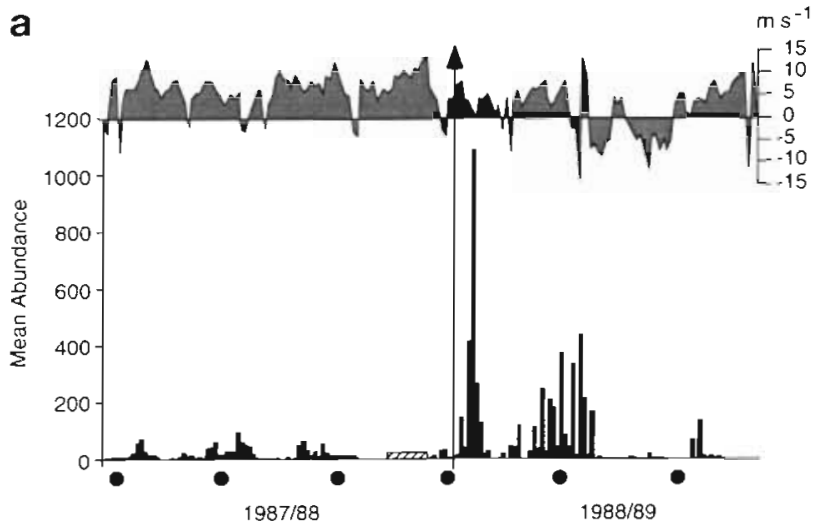

b
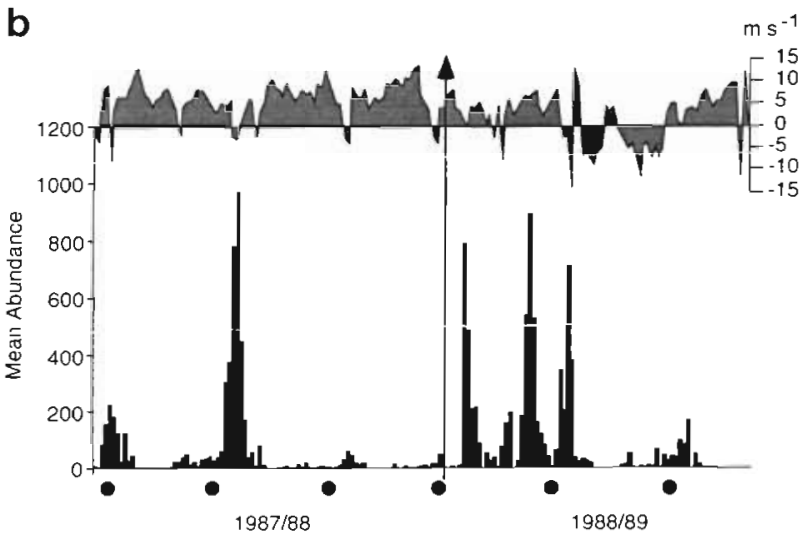

Fig. 3. Mean daily abundance of pomacentrids in light traps over the 2 years. Circles denote new moon periods. Area plot at top: wind stress as in Fig. 2. (a) Back-reef catches (hatched area identifies missing days); (b) front-reef catches

with time. No significant cycling was detected in the series. As expected from the above results, the correlation between barometric pressure and the wind component was positive (Fig. 2b). Thus, as the barometric pressure decreased, frequency of winds onshore to the back-reef habitat increased. The inter-seasonal decline in barometric pressure is, therefore, associated with a between-season increase in the occurrence of winds blowing into the back-reef habitat.

\section{Larval supply}

Time series of catches at the family level show a proportional increase in larval supply in the back-reef habitat from the first to the second sampling year, for the pomacentrids, apogonids and blenniids (Figs. 3a to $5 \mathrm{a}$, Table 1). Larval supply into the front-reef habitat also showed a proportional increase across the 2 years (Figs. 3b to 5b), however, except for the apogonids (Table 1), this increase was much smaller (at least $40 \%$ less than in the back-reef habitat\}. 

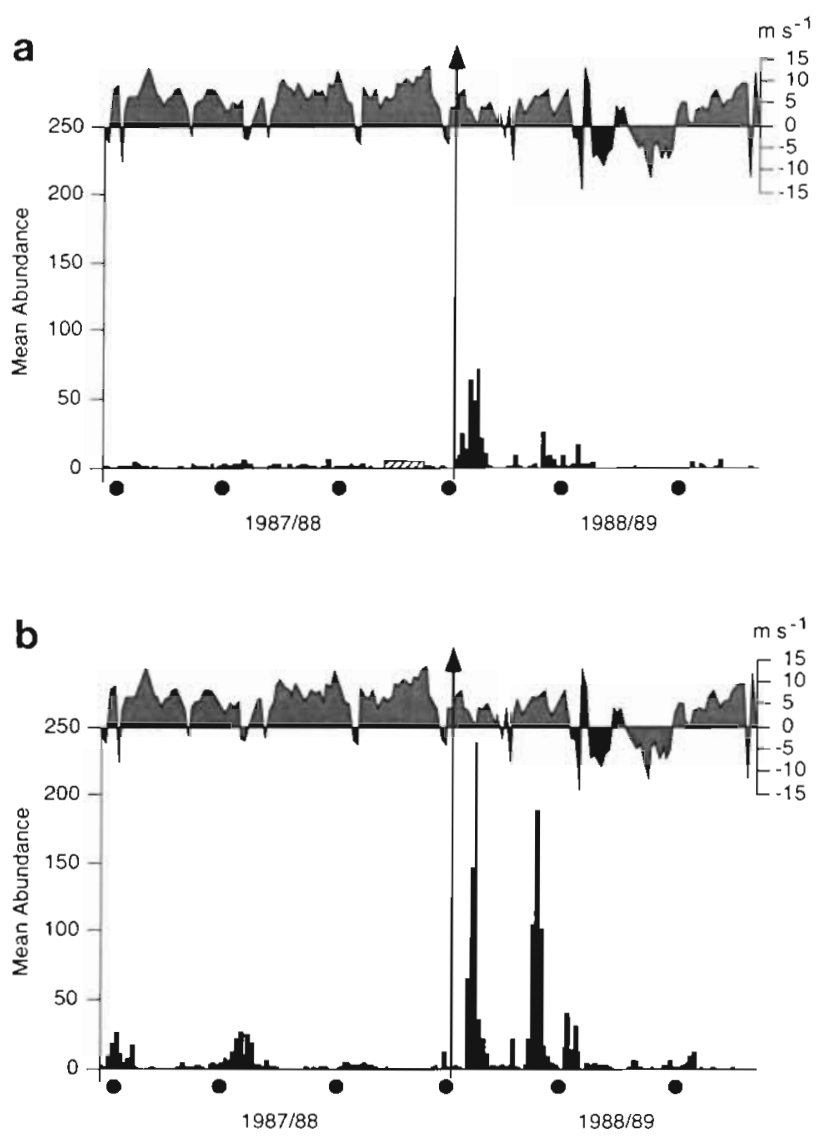

Fig. 4. Mean daily abundance of apogonids in light traps over the 2 years. Circles denote new moon periods. Area plot at top: wind stress as in Fig. 2. (a) Back-reef catches (hatched area identifies missing days); (b) front-reef catches

The pelagic group included in this analysis showed a unique pattern that may be expected of such a schooling, mixed-age group (Fig. 6). In contrast to the trend for the reef fish, catches in both the front-reef and back-reef habitats appeared, if anything, to decline between the 2 years (Table 1 ).

\section{Relationship between larval supply and physical factors}

Figs. 3 to 5 demonstate how the wind field compares to relative catch rates of the major reef fish families in the 2 habitats sampled in both seasons. Considering the back-reef habitat first, it is evident that the interseasonal trend in the total magnitude of larval supply is similar to the change that occurred in the wind field data. This tendency is apparent for all 3 of the reef fish families. Indeed for the Pomacentridae, a negative correlation exists between wind stress and the magnitude of larval supply to the back-reef habitat. Thus, as winds into the back-reef habitat increased in frequency so did larval supply (Fig. 7a). The same trend is apparent for the apogonids, although the cross-correlation coefficients are not significant at the $95 \%$ level (Fig. 7 b). Larval supply of blenniids and wind stress are significantly negatively correlated at a lag of $5 \mathrm{~d}$ which suggests that wind events some 5 d earlier may have pushed larvae towards Lizard Island from elsewhere.

Regarding the front-reef habitat, no correlation between wind stress and the magnitude of larval supply is immediately apparent from any of the plots in Figs. 3 to 5 . In fact, larval supply in the front-reef habitat increased between seasons while the winds onshore into this habitat decreased in frequency. This is reflected by a significant negative correlation between larval supply into the front-reef habitat and wind stress for both the pomacentrids and the blenniids (Fig. 7e, g). There was no significant correlation between wind stress and larval supply of apogonids (Fig. 7f), and a conflicting positive coefficient was present in the pomacentrid analysis at a lag of $-2 \mathrm{~d}$ (Fig. 7e). These results are almost certainly related to
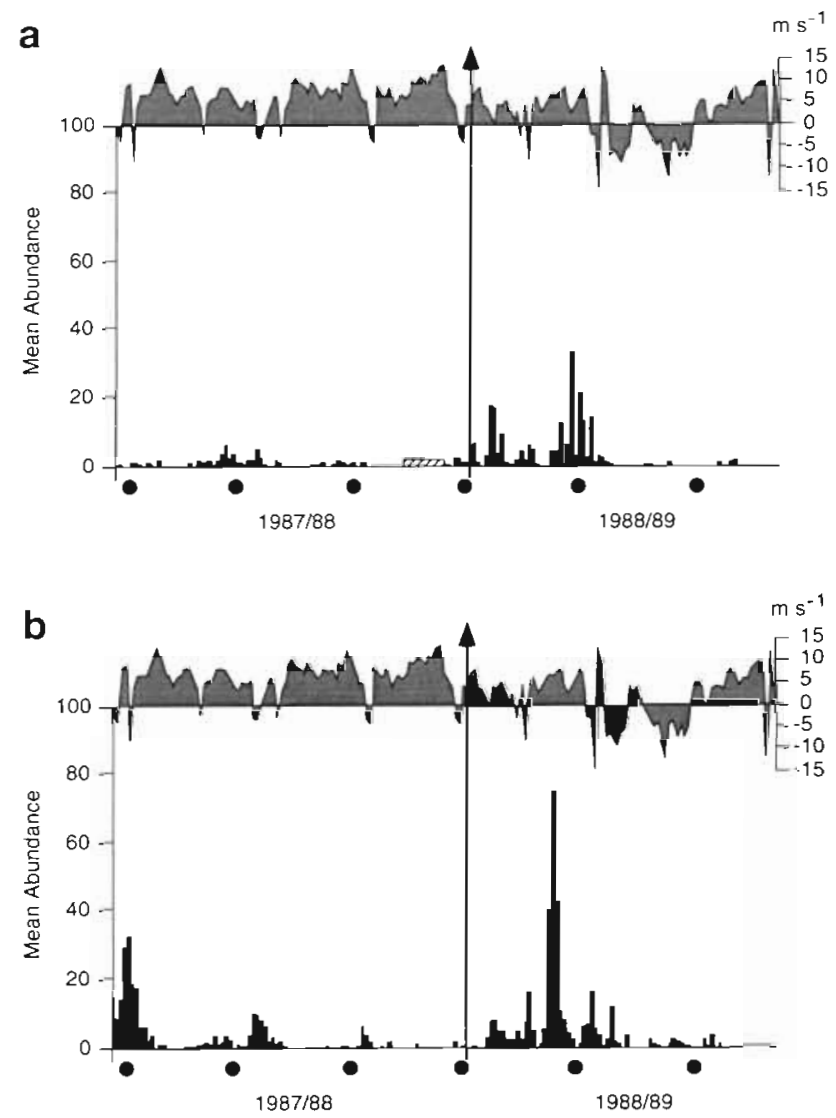

Fig. 5. Mean daily abundance of blenniids in light traps over the 2 years. Circles denote new moon periods. Area plot at top: wind stress as in Fig. 2. (a) Back-reef catches (hatched area identifies missing days); (b) front-reef catches 
Table 1. Total mean daily abundance of each family, in each year and habitat. Circles refer to proportional change between years (solid: positive; open: negative)

\begin{tabular}{|c|c|c|c|c|c|c|}
\hline \multirow[t]{2}{*}{ Taxa } & \multicolumn{2}{|c|}{ Front-reef } & \multirow{2}{*}{$\begin{array}{l}\text { Proportional } \\
\text { change }\end{array}$} & \multicolumn{2}{|c|}{ Back-reef } & \multirow{2}{*}{$\begin{array}{c}\text { Proportional } \\
\text { change }\end{array}$} \\
\hline & Year 1 & Year 2 & & Year 1 & Year 2 & \\
\hline Pomacentrids & 5184 & 7649 & $\bullet$ & 1455 & 5321 & \\
\hline Apogonids & 299 & 1186 & 0 & 67 & 384 & \\
\hline Blenniids & 229 & 331 & $\bullet$ & 56 & 210 & \\
\hline Pelagics & 2681 & 1595 & O & 1693 & 1389 & 。 \\
\hline
\end{tabular}

strated that under a light southeasterly wind influence, water flow bifurcates around the high continental island leaving a 'dead space' on the western side. The exact position of this low flow area is dependent on tidal state (Black \& Gay 1987), but it coincides well with the embayment area where the light traps were deployed (see Fig. 1 in Milicich \& Doherty 1994). This wind-depen-

the higher degree of intra-annual variability in the magnitude of larval supply that occurred on this frontreef side; events on single days will have a much higher impact on overall correlation values. The final plot in the series (Fig. 6) demonstrates the relative insensitivity of the schooling pelagic fishes to changes in the windfield. Catches were similar between the 2 habitals in both years and showed no obvious intuitive relationship with changes in wind stress (Fig. $7 \mathrm{~d}, \mathrm{~h}$ ). This confirms the suggestion that the relationship between wind direction and light trap catches appears to relate solely to the replenishment process.

\section{DISCUSSION}

Determining the causes of variability in the replenishment of fish populations is a major focus of fisheries ecology. While studies on commercially important populations in northern temperate waters have emphasised the role of various oceanographic phenomena in the control of recruitment variability, little comparable work has been attempted with tropical or reef fish populations. Various complex oceanographic factors have been found to be associated with coral reefs, headlands and continental islands (Alldredge \& Hamner 1980, Wolanski et al. 1984, Wolanski \& Hamner 1988, Kingsford 1990, Kingsford et al. 1991). These transitory processes form a rich mosaic of circulation patterns around reefs and are known to influence the distribution patterns of eggs, invertebrates and pre-settlement fish (references as above).

The results of this study suggest that wind forcing may explain at least some of the inter-habitat and inter-annual variability in the replenishment of reef fish populations. Specifically, it appears that at Lizard Island changes in the inter-annual intensity of onshore, westerly winds into the back-reef habitat are correlated with similar changes in the magnitude of larval supply. This effect can be best interpreted with an understanding of the topography of both the fringing reef and the island itself.

Two-dimensional modeling of wind and tide-influenced currents around Lizard Island have demon- dent shadow provides a simple explanation for gross changes in back-reef catch rates, since significant exchange and flow of water into this habitat will only occur during periods of westerly wind flow. Thus, during the second season of sampling when these winds increased in frequency, transport of competent larvae into the back-reef habitat may have been aided to such an extent that the overall level of repienishment strongly increased over the previous season.
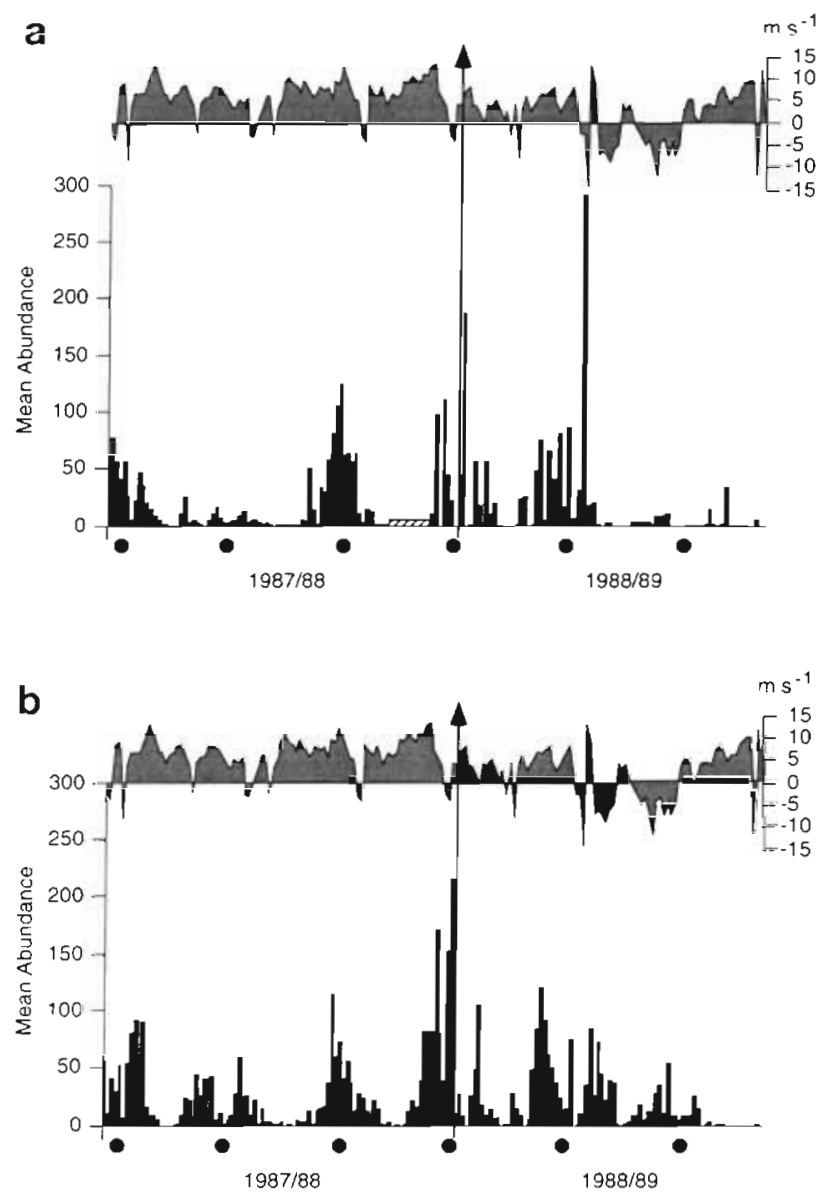

Fig. 6. Mean daily abundance of pelagic schooling fishes in light traps over the 2 years. Circles denote new moon periods. Area plot at top: wind stress as in Fig. 2. (a) Back-reef catches (hatched area identifies missing days); (b) front-reef catches 

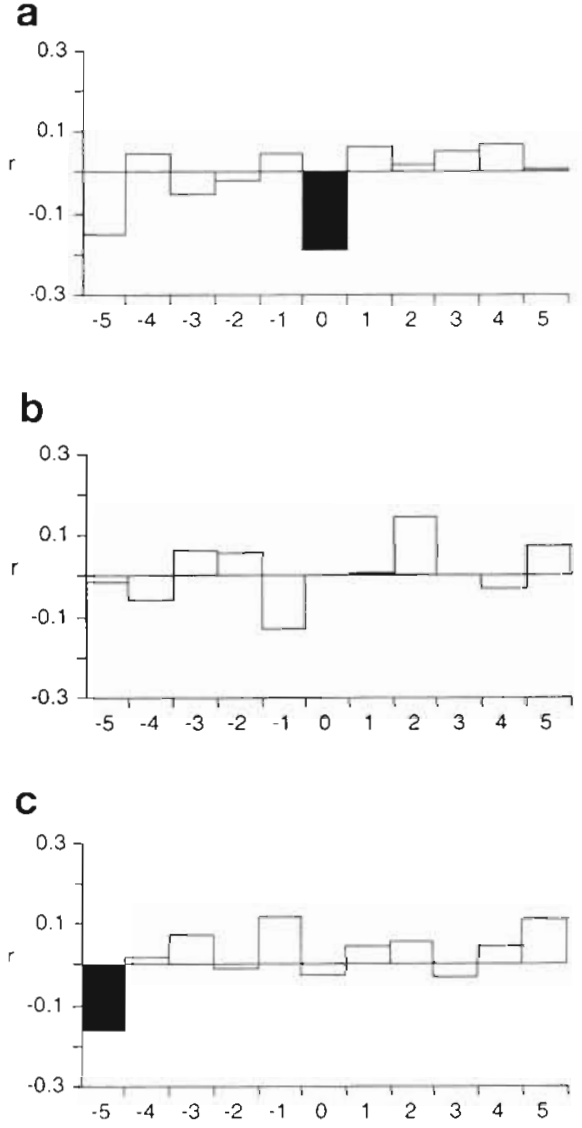

Fig. 7. Cross-correlation coefficients ( -5 to $5 \mathrm{~d}$ lag) of match between wind stress data and larval supply to (a to d) front-reef and (e to g) back-reef habitats. Solid bars are significant $(\alpha=$ 0.05). (a \& e) Pomacentrids; (b \& f): apogonids; (c \& g) blenniids: (d \& h) pelagic schooling fishes e

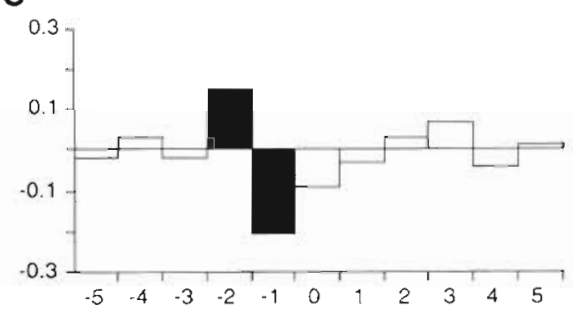

f

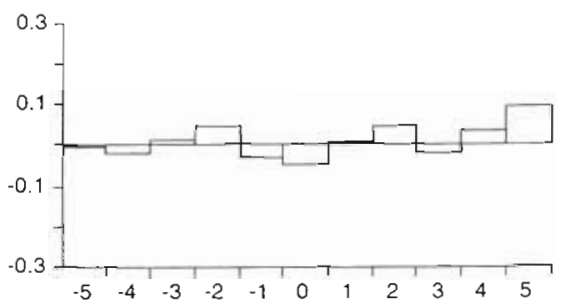

g
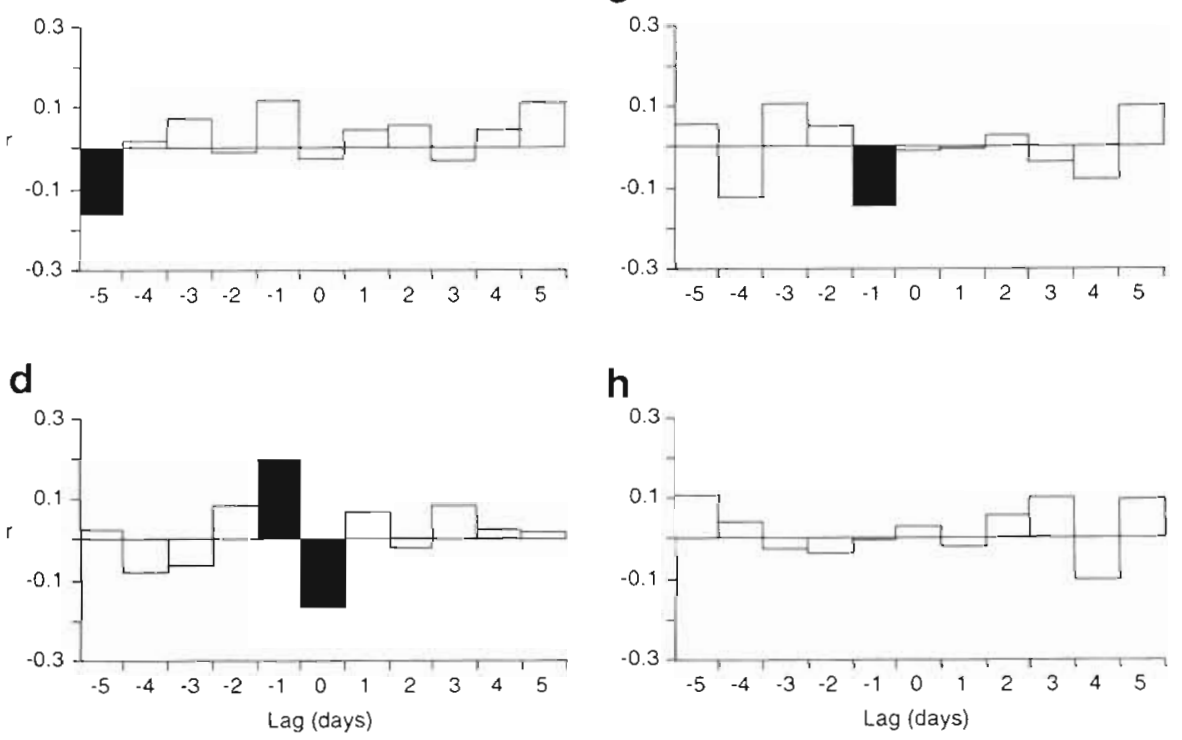

h

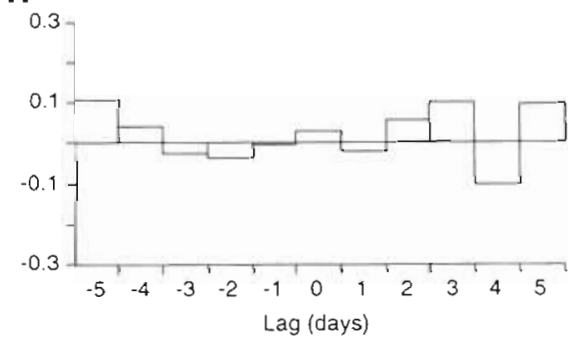

Investigation of barometric pressure allows this hypothesis to be extended to regional spatial scales. From April to October, the weather in the Lizard Island region is generally controlled by high pressure systems that ridge up the coast of Queensland, Australia (Andrews \& Pickard 1990). These systems cause an intensification of southeasterly winds that are often referred to as the southeast trades. However, from December to March, the monsoonal trough, a low pressure system that sits above Australia during most of the year often moves into the region, generating northwest winds (Wolanski et al. 1981). As the replenishment season in this region runs from October through to February, it is characterised by highly variable winds as these pressure systems oscillate back and forth.
These characteristics of the weather system are well reflected by the trends in the barometric pressure. The seasonal cycling identified in this variable is within the 1 wk to 1 mo range of oscillations that are known to occur on the GBR (Andrews \& Pickard 1990). The declining trend in pressure as the replenishment season progressed is consistent with a seasonal intensification of the monsoonal pressure system. Of more interest to the present application is the increased strength of this effect during the second sampling season. The monsoonal trough appeared to have more influence in the region during this season which correlates well with the observation of an increase in the frequency of westerly winds. These observations suggest that macro-scale changes in the weather system 
may be a good predictor of inter-annual changes in the replenishment of reef fish at a meso-scale level.

The situation on the front-reef side is far more complex. Correlations between the wind field and larval supply suggest that, counter-intuitively, inter-annual replenishment into the front-reef habitat increases as onshore winds decrease in intensity. Considering that current flow in this region is primarily wind driven (Wolanski \& Ruddick 1981, Frith et al. 1986), it is hard to envisage how such inter-annual trends could be explained by simple hydrodynamics. Does this mean that the physical model discussed earlier is invalid as an explanation for inter-annual changes in larval supply?

The edge of the front-reef habitat runs in an almost straight line up the nor theast to southwest aspect of the island (see Fig. 1 in Milicich \& Doherty 1994) and is fully exposed to tidal and onshore wind flow. In contrast, the back-reef habitat is shallower and characterised by a concave reef edge that is sheltered by headlands on either side. Although published runs of the 2-dimensional model considered earlier have not inciuded simulations involving westerly wind influences, the less protected nature of the front-reef habitat indicates that there should be a considerable exchange of water in this habitat, irrespective of the wind direction. This is in direct contrast to the 'dead space' phenomenon that occurs in the sheltered backreef embayment. Thus, the same hydrodynamic model predicts that wind stress should have a high impact on larval supply into the back-reef habitat, but not into the front-reef habitat.

What then might be determining inter-annual changes in levels of larval supply into this front side of the island? Larval supply is but the final link in a complex chain of events that begins with spawning and advances through a pelagic stage that lasts anywhere from weeks to months (e.g. Brothers et al. 1983, Kingsford \& Milicich 1987). Evidence collected to date suggests that the magnitude of spawning has little effect on variability in levels of larval supply (Robertson et al. 1988, Meekan et al. 1993). This implies that the rnagnitude of replenishment is influenced by a range of planktonic processes, of which those operating near settlement are but a part. Starvation, predation and advection of larvae are 3 possible candidates that may explain some of the variability in larval supply events that occur inter-annually in the front-reef habitat, and intra-seasonally in both habitats (e.g. Lasker 1981, Hunter 1981, Sinclair et al. 1985).

One other strong feature of the larval supply data was the observation that front-reef catch rates were consistently higher than those in the back-reef habitat, irrespective of any inter-annual trends within either habitat. The results of a clod card dissolution study
(Milicich 1992) show that the only time that water flow in the front-reef habitat fell below rates in the backreef habitat was when strong westerly winds prevailed. At all other times, movement of water in the front-reef habitat was higher than in any other habitat sampled. This corroborates the suggestion from the hydrodynamic model that the link between larval supply and wind stress on this front-reef side is unlikely to be a simple one, if indeed a relationship exists at all.

Adding a further layer of complexity, Leis (1986) and Leis \& Goldman (1987) suggest that there may be a retentive mechanism operating on the front-reef side of the island. If true, this may also partially explain the consistently high catches in this habitat. The evidence for this mechanism is both biological and physical. Assemblages of early larval stages were found to be asymmetric across the front and back-reef sides of the island. The back side was characterised by a transient assemblage, while a more stable assemblage including some post-flexion forms (not yet competent to settle), persisted on the front. The physical data were based on drogue measurements and suggested that residual flow on the front side moved north and south according to tidal state. In contrast, residual flow on the back side, particularly at the surface, was always to the south despite being subdued by the ebb tide. These data were collected when winds were predominantly from the southeast (i.e. onshore to the front-reef habitat). Frith (1983) suggested that under these conditions a convergence zone may result from the offshore movement of deeper water at the reef edge. If present, this zone would act to entrap buoyant particles at the surface or maintain the position of surface-oriented organisms. This provides an intuitive explanation for the possibility of a retention mechanism on the frontreef side, which is in agreement with the observations of continually higher levels of larval supply into this habitat. However, this mechanism cannot explain the trend for increased larval supply in this habitat between years, since there was a decrease in the winds necessary to drive the convergence zone.

Inter-annual and habitat trends aside, larval supply of reef fish is often characterised by considerable fluctuation in the magnitude of successive supply events that occur in distinct pulses throughout the season, i.e. the data are highly non-linear and episodic. While model filters can reduce these effects, the validity of relying on linear correlation analysis to describe relationships between these data and other time series must be under some doubt (Sugihara \& May 1990). One obvious problem is the difficulty of comparing physical data to replenishment data where there has been no larval supply event. Clearly this will weaken any correlation not because there may be no relationship but simply because there were no larvae in the 
water column at that time. In the present study this problem was minimised by integrating larval supply over all species in each family. Even with this approach there are still times when minimal replenishment occurred. Replenishment of reef fish at Lizard Island has shown strong lunar cycling just after the new moon in some species which may be related to spawning rhythms (Milicich unpubl.). It would seem sensible to look at the correlation between physical and replenishment data only for a few days around the new moon. However, perusal of any of the time series in Figs. 3 to 5 shows that this criterion would omit many significant larval supply events; spawning rhythms are variable and events occurring in the pelagic environment also influence the timing of larval supply (Milicich unpubl.). Another possibility is to only consider those days when larval supply was above some nominated level. This disrupts the continuity of the series and prevents detection of any biologically significant lag effects between physical and larval supply data. A delay effect was detected for the blenniids suggesting that winds $5 \mathrm{~d}$ prior to at least 1 larval supply event were important in delivering larvae to Lizard Island. Perhaps given these problems the real surprise is that there were any significant correlations at all. In this particular study, inter-annual changes in larval supply and the wind field were obviously quite strong and clear; it may be expected that more subtle patterns will not be detected as easily by this analytical approach. Alternative ways of analysing these relationships are currently being developed using this data set and results will be reported elsewhere.

In conclusion, for the back-reef habitat of Lizard Island, there appears to be a real and quantifiable correlation between wind stress and inter-annual changes in the level of larval supply. This process correlates with large-scale changes in the weather system which suggests that the relationship may operate on similar reefs and be predictable at a region-wide scale. Results for the front-reef habitat suggest that wind stress may be less important to influencing interannual levels of replenishment. A local retention mechanism may act to keep replenishment in the front-reef habitat relatively high, but even so, results suggest that processes operating prior to larval supply may be more important in determining inter-annual fluctuations in the magnitude of replenishment to this habitat.

Acknowledgements. I thank P. Doherty for his support and encouragement and for providing invaluable comments on the original version of this manuscript. Helpful criticisms were also made by P. Sale, M. Sinclair and I. Suthers. This work was conducted while I was a holder of a Postgraduate Scholarship from Griffith University and a Lizard Island Postgraduate Fellowship from the Australian Museum. Further funding was made available by awards from The Australian Coral Reef Society and The Great Barrier Reef Marine Park Authority. Many people helped me during my lengthy sojourn in the field; thanks to J. Davidson, P. Dempsey, D. Grice, M. McCormick, L. Mcllwain, K. Milicich, A. Page, A. Rogers, Rowena, B. Gardener and L. Whiteley. I would also like to acknowledge the support of the Lizard Island Research Station and the Australian Institute of Marine Science. Finally, thanks to J. Shenker of the Florida Institute of Technology for generously providing me with space to work and access to computer facilities.

\section{LITERATURE CITED}

Alldredge, A. L., Hamner, W. M. (1980). Recurring aggregation of zooplankton by a tidal current. Estuar. coast. mar. Sci. 10: 31-38

Andrews, J. C., Pickard, G. L. (1990). The physical oceanography of coral-reef systems. In: Dubinsky, Z. (ed.) Coral reefs. Elsevier Science Publishers, New York, p. 11-48

Anthony, V. C., Fogarty, M. J. (1985). Environmental effects on recruitment, growth, and vulnerability of Atlantic herring (Clupea harengus) in the Gulf of Maine region. Can. J. Fish. Aquat. Sci. 42 (Suppl. 1): 158-173

Black, K. P., Gay, S. L. (1987). Hydrodynamic control of the dispersal of crown-of-thorns larvae. I. Small scale hydrodynamics on and around schematized and actual reefs. Victorian Inst. mar. Sci. Tech. Rep. 8: 1-67

Brothers, E. B., Williams, D. McB., Sale, P. F. (1983). Length of larval life in twelve families of fishes at 'One Tree Lagoon', Great Barrier Reef, Australia. Mar. Biol. 76: 319-324

Chatfield, C. (1979). The analysis of time series: an introduction. Chapman and Hall, London

Cowen, R. K. (1985). Large scale pattern of recruitment by the labrid, Semicossyphus pulcher: causes and implications J. mar. Res. 43: 719-742

Doherty, P. J. (1987). Light traps: selective but useful devices for quantifying the distributions and abundances of larval fishes. Bull. mar. Sci. 41: 423-431

Doherty, P. J., Fowler, A. J. (1994). An empirical test of recruitment limitation in a coral reef fish. Science 263: 935-939

Dufour, V. (1991). Variations of fish larvae abundance in reefs: effect of light on the colonisation of the reefs by fish larvae. C.r. Acad. Sci. Paris 313: 187-194

Epifanio, C. E., Masse, A. K., Garvine, R. W. (1989). Transport of blue crab larvae by surface currents off Delaware Bay, USA. Mar. Ecol. Prog. Ser. 54: 35-41

Frith, C. A. (1983). Windward reef circulation, Davies Reef, central Great Barrier Reef. In: Baker, J. T, Carter, R. M. Sammarco, P. W. Starck, K. P. (eds.) Proc. Inaug. Great Barrier Reef Conf.. James Cook University Press, Townsville, p. 435-440

Frith, C. A., Leis, J. M., Goldman, B. (1986). Currents in the Lizard Island region of the Great Barrier Reef and their relevance to potential movements of larvae. Coral Reefs 5: $81-92$

Hamner, W. M., Schneider, D. (1986). Regularly spaced rows of medusae in the Bering Sea: role of Langmuir circulation. Limnol. Oceanogr. 31: 171-177

Hunter, J. R. (1981). Feeding ecology and predation of marine fish larvae. In: Lasker, R. (ed.) Marine fish larvae: morphology, ecology and relation to fisheries. Univ. of Washington Press, Seattle, p. 33-77

Kingsford, M. J. (1990). Linear oceanographic features: a focus for research on recruitment processes. Aust. J. Ecology 15: 391-401 
Kingsford, M. J., Choat, J. H. (1985). The fauna associated with drift algae captured with a plankton-mesh purse seine net. Limnol. Oceanogr. 30: 618-630

Kingsford, M. J., Choat, J. H. (1986). Influence of surface slicks on the distribution and onshore movements of small fish. Mar. Biol. 91: 161-171

Kingsford, M. J., Milicich, M. J. (1987). Presettlement phase of Parika scaber (Pisces: Monacanthidae): a temperate reef fish. Mar. Ecol. Prog. Ser. 36: 65-79

Kingsford, M. J., Wolanski, E., Choat, J. H. (1991). Influence of tidally induced fronts and Langmuir circulations on the distribution and movements of presettlement fishes around a coral reef. Mar. Biol. 109: 167-180

Lasker, R. (1981). The role of a stable ocean in larval fish survival and subsequent recruitment. In: Lasker, R. (ed.) Marine fish larvae: morphology, ecology and relation to fisheries. Univ. of Washington Press, Seattle, p. 80-87

Leggett, W. C., Frank, K. T., Carscadden, J. E. (1984). Meteorological and hydrographic regulation of year-class strength in capelin (Mallotus villosus). Can. J. Fish. Aquat. Sci. 41: 1193-1201

Leis, J. M. (1986). Vertical and horizontal distributions of fish iarvae near cordi reefs at Lizard isiand, Great Barrier Reef. Mar. Biol. 90: 505-516

Leis, J. M., Goldman, B. (1987). Composition and distribution of larval fish assemblages in the Great Barrier Reef lagoon, near Lizard Island, Australia. Aust. J. mar. Freshwat. Res. 38: 211-223

McFarland, W. N., Brothers, E. B., Ogden, J. C., Shulman, M. J., Bermingham, E. L., Kotchian-Prentiss, N. M. (1985). Recruitment patterns in young french grunts, Haemulon flavolineatum (family Haemulidae) at St. Croix, U. S. Virgin Islands. Fish. Bull. U.S. 83: 413-426

Meekan, M. G., Milicich, M. J., Doherty, P. J. (1993). Spawning determines temporal patterns of replenishment in a coral reef fish. Mar. Ecol. Prog. Ser. 93: 217-225

Milicich, M. J. (1988). The distribution and abundance of presettlement fish in the nearshore waters of Lizard Island Proc. 6th int. coral Reef Symp. 2: 785-790

Milicich, M. J. (1992). Light traps: a novel technique for monitoring larval supply and replenishment of coral reef fish populations. Ph.D. thesis, Griffith University, Brisbane

Milicich, M. J., Doherty, P. J. (1994). Larval supply of coral reef fish populations: magnitude and synchrony of replenishment to Lizard Island, Great Barrier Reef. Mar. Ecol.

This article was presented by D. Alongi (Senior Editorial Advisor), Townsville, Australia
Prog. Ser. 110: 121-134

Milicich, M. J., Meekan, M. G., Doherty, P. J. (1992). Larval supply; a good predictor of recruitment of three species of reef fish (Pomacentridae). Mar. Ecol. Prog. Ser. 86: $153-166$

Robertson, D. R., Green, D. G., Victor, B. C. (1988). Temporal coupling of reproduction and recruitment of larvae of a Caribbean reef fish. Ecology 69: 370-381

Shanks, A. L. (1983). Surface slicks associated with tidally forced internal waves may transport pelagic larvae of benthic invertebrates and fishes shoreward. Mar. Ecol. Prog. Ser. 13: 311-315

Shenker, J. M., Maddox, E. D., Wishinski, E., Pearl, S., Thorrold, S. R., Smith, N. (1993). Onshore transport of settlement-stage Nassau grouper Epinephelus striatus and other fishes in Exuma Sound, Bahamas. Mar. Ecol. Prog. Ser. 98: $37-43$

Sinclair, M., Tremblay, M. J., Bernal, P. (1985). El Nin̄o events and variability in a Pacific mackerel (Scomber japonicus) survival index: support for Hjort's second hypothesis. Can. J. Fish. Aquat. Sci. 42: 602-608

Sissenwine, M. P. (1984). Why do fish populations vary? In: May, R. M. (ed.) Exploitation of marine communities. Springer-Verlag, Berlin, p. 59-94

Sugihara, G., May, R. M. (1990). Nonlinear forecasting as a way of distinguishing chaos from measurement error in time series. Nature 344: 734-741

Thorrold, S. R., Snenker, J., Maddox, M. E., Mojica, K, Wishinski, E. (1993). Lunar and oceanographic influences on the supply of fish larvae to nursery habitats around Lee Stocking Island, Exuma Cays, Bahamas. Mar. Biol. 118: $567-578$

Wolanski, E., Hamner, W. M. (1988). Topographically controlled fronts in the ocean and their biological significance. Science 241: 177-181

Wolanski, E., Imberger, J., Heron, M. L. (1984). Island wakes in shallow coastal waters. J. geophys. Res. 89(C6): $10553-10569$

Wolanski, E., Jones, M., Williams, W. T. (1981). Physical properties of Great Barrier Reef lagoon waters near Townsville. II. Seasonal variations. Aust. J. mar. Freshwat. Res. 32: $321-334$

Wolanski, E., Ruddick, B. (1981). Water circulation and shelf waves in the northern Great Barrier Reef Lagoon. Aust. J. mar. Freshwat. Res. 32: 721-740

Manuscript first received: September 1, 1993

Revised version accepted: March 15, 1994 